\title{
Factors that Motivate Participation in Observational Genetic Cancer Research Studies
}

\author{
Deborah Goodman ${ }^{1}$, Catherine 0. Johnson ${ }^{2}$, Deborah Bowen ${ }^{3}$, Lari Wenzel ${ }^{4}$, Karen Edwards ${ }^{1}$ \\ ${ }^{1}$ Department of Epidemiology, University of California, Irvine, CA, USA \\ ${ }^{2}$ Institute for Health Metrics and Evaluation, Seattle, WA, USA \\ ${ }^{3}$ School of Public Health, University of Washington, Seattle, WA, USA \\ ${ }^{4}$ Department of Public Health, University of California, Irvine, CA, USA \\ Email: *goodmand@uci.edu
}

How to cite this paper: Goodman, D., Johnson, C.O., Bowen, D., Wenzel, L. and Edwards, K. (2019) Factors that Motivate Participation in Observational Genetic Cancer Research Studies. Open Journal of Epidemiology, 9, 156-172.

https://doi.org/10.4236/ojepi.2019.92014

Received: March 21, 2019

Accepted: May 24, 2019

Published: May 27, 2019

Copyright (c) 2019 by author(s) and Scientific Research Publishing Inc. This work is licensed under the Creative Commons Attribution International License (CC BY 4.0).

http://creativecommons.org/licenses/by/4.0/

\begin{abstract}
Demographics, access to new treatment, altruistic motivations and continuity of care have been shown to influence motivation to participate in clinical trials. Less is known however, about factors that motivate research participants to agree to take part in observational studies and provide a biologic specimen. This study evaluates and quantitates factors that motivate participation in observational studies and provide a biospecimen among cancer patients, their family members, and controls. An online survey was completed by 450 participants from a cancer genetics registry, including cancer patients, their relatives, and controls. Overall, the benefit to society and the research institution reputation were the most important motivators for participation. Cancer cases were significantly more likely to endorse personal meaningfulness as a factor for participation compared to those without cancer and women were 50\% more likely than men to believe that a family benefit is an important determinant of research participation. Researcher and institutional trustworthiness as well as security of stored data were most important when deciding whether to provide a biological sample, with differences seen by gender and history of cancer. This study demonstrated which factors are most important to participants when considering participation in an observational study and donating a biospecimen. Motivational factors significantly differed by gender as well as history and stage of cancer. The application of these study results may improve participation rates in cohort studies.
\end{abstract}

\section{Keywords}

Participation, Research, Motivation, Observational Studies 


\section{Introduction}

The Precision Medicine Initiative (PMI) will enroll a million or more participants in a cohort program with the goal of learning about disease risk, discovering new disease biomarkers, expanding our knowledge of pharmacogenomics, and finding targeted and individualized treatment of diseases [1]. An understanding of research subject selection is critical. It is important to recruit from a broad population-representative sample to maximize generalizability of findings and minimize potential bias. An understanding of factors that influence participation in an observational longitudinal research study will enhance recruitment, improve study retention, and increase external validity.

It is well documented that participation in research studies is influenced by participant demographics including age, ethnicity, socioeconomic status, and gender [2] [3] [4] [5]. In addition to demographic predictors of participation, specific motivations like self-gain, or altruism, have been linked with participation [6]. Evaluating motivational factors that influence participation in clinical trials, several studies have shown that the most common reasons for participation include access to new treatment [7] [8], altruistic motivations [7] [8] [9] [10] [11] and continuity of care [11]. Unlike clinical trials, however, participation in observational studies does not usually offer the benefit of continuity of care or access to new treatment. In addition, population-based cohort studies include both healthy, unaffected participants and those with a spectrum of illnesses found in the general population. It is important to understand how motivators for study participation may differ for a cohort design compared to a clinical trial and for a healthy versus a diseased population. Few studies have examined factors that promote participation in observational studies [12] [13] [14] [15] [16], and the majority of this previous research has used qualitative methods to examine this issue [12] [13] [14] [15], making cross study comparisons difficult.

The PMI program will consist of an observational cohort of individuals and families with a spectrum of health conditions. Participation will consist of several distinct components, including completion of baseline survey information, access to patient electronic medical records, and providing a biospecimen for banking. It is possible that participants' motivators differ for each of these components and multiple approaches will be required to successfully recruit for this large project. It is also possible that level or reason for motivation may vary depending on what type of participant is being recruited (for example, case compared with relative or a control). At a time when participation in epidemiologic research studies has been declining [17], the PMI strives to create a cohort of historic size. However, the best ways to attract and motivate participation in the PMI are not known. The present timely study will fill this gap by evaluating and quantitating factors that influence participation and provision of a biological sample among cancer patients, their family members, and controls in an observational longitudinal research study. 


\section{Materials and Methods}

\subsection{Eligibility and Recruitment for the Participant Issues and Expectations Project (PIP)}

The source population for the Participant Issues and Expectations Project (PIP) was the individuals $(n=3553)$ enrolled in the Northwest Cancer Genetics Registry (NWCGR), part of a national network designed to specialize in the study of inherited predisposition to cancer. The NWCGR was established in 2010 and has been described elsewhere [18]. This included people with cancer recruited from Western Washington $(n=2027)$, first-degree relatives of cases $(n=451)$, controls who were recruited from a random population sample from $\mathrm{W}$. Washington $(n=527)$, and people who self-referred in response to community awareness efforts and included both people with and without cancer ( $\mathrm{n}=904$ total; 340 with cancer). Self-referrals with cancer were grouped with cases and those without were grouped with the controls. There were no restrictions on the selection of controls or relatives. Letters, including informed consent, were sent by US mail in 2011 and 2012 inviting the enrolled individuals to take the online, confidential survey. Up to three invitations were sent to participants at approximately two-week intervals. Of the 450 participants that completed the online survey, 228 were from the case group, 155 were from the control group, and 67 were relatives.

\subsection{Survey Methods}

Development of the PIP Survey

The purpose of the survey was to document the range and frequency of occurrence of concerns and expectations regarding participating in human research studies, including genomic and family studies. Detailed methods for this study, including the survey instrument, have been published previously [19]. Briefly, the survey instrument had a total of 22 questions, divided into six general topic areas: decision to participate in research; relationship between researchers and participants; re-consent and broad consent; return of results; use and security of de-identified data; and family communication of health issues. The types of response categories included either yes/no/not sure options, Likert-scales (e.g., 5-point scales rating agreement, likelihood or importance of the statement with a sixth "don't know" or "it depends" option) or categorical responses. Nine scenarios asked about the factors that would influence their decision to participate in research and 4 scenarios covered factors related to factors that would influence whether they would provide a biological sample for genetic analysis. We report here the results of these13 items (see Appendix 1).

The survey was confidential, not anonymous, using a unique identification number for each participant, and participants were free to skip any questions that they did not wish to answer. Each participant was provided an individual URL to access the secure survey instrument. Links to each individual survey and the participant's NWCGR data were retained to reduce the length of the survey 
and to allow us to utilize existing demographic and other participant information.

All study procedures were approved by the University of Washington's $\mathrm{Hu}$ man Subjects Division, and also by the University of California, Irvine Institutional Review Board. All participants provided informed consent prior to participation.

\subsection{Statistical Analysis}

Responses to questions were first summarized using frequency distributions for the overall sample and by participant type (i.e., cases, controls, relatives). Ordinal logistic regression was the primary tool to evaluate the association between participant characteristics and participation in research and providing a biological sample for genetic analysis. Differences examined included status (cases versus controls versus relatives), gender, diagnosis of cancer at baseline, diagnosis of cancer at follow-up, and stage of cancer for cases reported at either baseline or follow-up. The response categories for the 13 questions (dependent variable) were the same and were ordered and coded as follows: 1) very important as 1 , somewhat important as 2 , not very important as 3 and not at all important as 4 . With ordinal logistic regression, several cumulative logits are modeled using all possible cut points of the dependent variable, but a single summary odds ratio (OR) and 95\% confidence interval describing the relationship between the dependent and independent variable is obtained. Comparisons were adjusted for age, gender and education. $\mathrm{R}$ version 3.2.2 was used for all analyses; the polr function from the MASS package was used for ordinal logistic regression) [20]. A p-value $\leq 0.05$ was considered statistically significant for all tests. Sample sizes varied slightly by question since participants were allowed to skip any question they did not wish to answer.

\section{Results}

About half of this study population consisted of cases $(n=228)$, one-third were controls $(n=155)$, and the remainder of the population was relatives $(n=67)$

(Table 1). Overall, the average participant age was 63.6 years, and the majority were white $(94.7 \%)$ and well educated, with over $60 \%$ of participants having a college degree. Compared to cases and relatives, controls were slightly more likely to be female. Among those participants with cancer at study enrollment, melanoma was the most frequent cancer type (29.5\%), followed by thyroid cancer (18.3\%), and breast cancer (15.5\%). Thirty-five research participants without cancer at enrollment reported a cancer at the time of this (follow-up) survey.

As shown in Table 2, the knowledge that the research could benefit society and the reputation of the research institution were the most important reasons to study participants when making the choice to participate in a research study, with $99 \%$ and 97 of participants, respectively, stating these factors were either very important or somewhat important to their decision. Over $80 \%$ of participants 
Table 1. Distribution of demographic characteristics of study population by participant type.

\begin{tabular}{|c|c|c|c|c|}
\hline & Total $(n=450)$ & Cases $(n=228)$ & Controls $(\mathrm{n}=155)$ & Relatives $(n=67)$ \\
\hline Mean (SD) Age (yrs) & $63.6(11.8)$ & $64.3(11.4)$ & $64.0(11.5)$ & $60.5(13.6)$ \\
\hline Women & $292(64.9 \%)$ & $145(63.6 \%)$ & $110(71.0 \%)$ & $37(55.2 \%)$ \\
\hline \multicolumn{5}{|l|}{ Race } \\
\hline Asian/Pacific Islander & $7(15.6 \%)$ & $4(1.8 \%)$ & $2(1.3 \%)$ & $1(1.5 \%)$ \\
\hline Black & $4(0.9 \%)$ & $2(0.9 \%)$ & $2(1.3 \%)$ & 0 \\
\hline Multi-Racial/Other & $16(3.6 \%)$ & $8(3.5 \%)$ & $4(2.6 \%)$ & $4(6.0 \%)$ \\
\hline White & $423(94.7 \%)$ & $214(93.9 \%)$ & $147(94.8 \%)$ & $62(92.5 \%)$ \\
\hline \multicolumn{5}{|l|}{ Education } \\
\hline High School or less & $40(8.9 \%)$ & $19(8.3 \%)$ & $13(8.4 \%)$ & $8(11.9)$ \\
\hline Some College & $107(23.8 \%)$ & $57(25.0 \%)$ & 37 (23.9\%) & $13(19.4 \%)$ \\
\hline Bachelors Degree & $276(61.3 \%)$ & $126(55.3 \%)$ & $105(67.7 \%)$ & $45(67.2 \%)$ \\
\hline Unknown & $27(6.0 \%)$ & $26(11.4 \%)$ & 0 & $1(1.5 \%)$ \\
\hline
\end{tabular}

Table 2. Frequency (\%) of responses overall and by participant type to the question: "When making the decision to participate in a research study, how important are the following to you?"

\begin{tabular}{|c|c|c|c|c|}
\hline & Total & Cases & Controls & Relatives \\
\hline \multicolumn{5}{|c|}{$\begin{array}{l}\text { The reputation of the research institution or } \\
\text { researcher }\end{array}$} \\
\hline Very important & $346(77.1)$ & $176(77.2)$ & $121(78.1)$ & $49(74.2)$ \\
\hline Somewhat important & $89(19.8)$ & $42(18.4)$ & $32(20.6)$ & $15(22.7)$ \\
\hline Not very important & $8(1.8)$ & $5(2.2)$ & $1(0.6)$ & $2(3.0)$ \\
\hline Not at all important & $6(1.3)$ & $5(2.2)$ & $1(0.6)$ & $0(0)$ \\
\hline \multicolumn{5}{|c|}{$\begin{array}{l}\text { The value of incentives (for example, gift cards } \\
\text { or cash) }\end{array}$} \\
\hline Very important & $16(3.6)$ & $6(2.7)$ & $7(4.5)$ & $3(4.5)$ \\
\hline Somewhat important & $75(16.8)$ & $43(19.0)$ & $22(14.3)$ & $10(15.2)$ \\
\hline Not very important & $179(40.1)$ & $89(39.4)$ & $67(43.5)$ & $23(34.8)$ \\
\hline Not at all important & $176(39.5)$ & $88(38.9)$ & $58(37.7)$ & $30(45.5)$ \\
\hline \multicolumn{5}{|c|}{$\begin{array}{l}\text { The research must be meaningful to me } \\
\text { personally }\end{array}$} \\
\hline Very important & $204(45.6)$ & $109(48)$ & $64(41.6)$ & $31(47)$ \\
\hline Somewhat important & $172(38.5)$ & $87(38.3)$ & $60(39)$ & $25(37.9)$ \\
\hline Not very important & $44(9.8)$ & $18(7.9)$ & $18(11.7)$ & $8(12.1)$ \\
\hline Not at all important & $27(6.1)$ & $13(5.7)$ & $12(7.8)$ & $2(3.0)$ \\
\hline \multicolumn{5}{|c|}{ The research will improve my health } \\
\hline Very important & $110(24.7)$ & $57(25.2)$ & $31(20.1)$ & $22(33.3)$ \\
\hline
\end{tabular}




\section{Continued}

$$
\begin{gathered}
\text { Somewhat important } \\
\text { Not very important } \\
\text { Not at all important } \\
\text { The research will provide in } \\
\text { use to improve my health } \\
\text { Very important } \\
\text { Somewhat important } \\
\text { Not very important } \\
\text { Not at all important }
\end{gathered}
$$

The research will provide information I can

The research will provide information about me I didn't know

Very important
Somewhat important
Not very important
Not at all important

The research could benefit my family

$$
\begin{aligned}
& \text { Very important } \\
& \text { Somewhat important } \\
& \text { Not very important } \\
& \text { Not at all important }
\end{aligned}
$$

The research could benefit people I know

$$
\begin{aligned}
& \text { Very important } \\
& \text { Somewhat important } \\
& \text { Not very important } \\
& \text { Not at all important }
\end{aligned}
$$

The research could benefit society

Very important
Somewhat important
Not very important
Not at all important

$\begin{array}{llll}190(42.6) & 98(43.4) & 69(44.8) & 23(34.8) \\ 99(22.2) & 49(21.7) & 38(24.7) & 12(18.2) \\ 47(10.5) & 22(9.7) & 16(10.4) & 9(13.6)\end{array}$

$150(33.6) \quad 76(33.8) \quad 47(30.3) \quad 27(40.9)$

$186(41.7) \quad 101(44.9) \quad 68(43.9) \quad 17(25.8)$

$77(17.3) \quad 36(16) \quad 27(17.4) \quad 14(21.2)$

$33(7.4) \quad 12(5.3) \quad 13(8.4) \quad 8(12.1)$

$\begin{array}{llll}129(29.0) & 67(29.8) & 42(27.3) & 20(30.3) \\ 173(38.9) & 89(39.6) & 64(41.6) & 20(30.3) \\ 98(22.0) & 48(21.3) & 31(20.1) & 19(28.8) \\ 45(10.1) & 21(9.3) & 17(11.0) & 7(10.6)\end{array}$

$\begin{array}{cccc}262(58.7) & 134(59) & 85(55.6) & 43(65.2) \\ 132(29.6) & 72(31.7) & 46(30.1) & 14(21.2) \\ 34(7.6) & 11(4.8) & 17(11.1) & 6(9.1) \\ 18(4.1) & 10(4.4) & 5(3.3) & 3(4.5)\end{array}$

$\begin{array}{cccc}240(53.9) & 126(55.5) & 76(49.7) & 38(58.5) \\ 147(33.0) & 75(33.0) & 52(34) & 20(30.8) \\ 41(9.2) & 17(7.5) & 20(13.1) & 4(6.2) \\ 17(3.9) & 9(4.0) & 5(3.3) & 3(4.6)\end{array}$

\begin{tabular}{cccc}
$360(81.1)$ & $183(81)$ & $124(81.6)$ & $53(80.3)$ \\
$80(18.0)$ & $41(18.1)$ & $26(17.1)$ & $13(19.7)$ \\
$3(0.7)$ & $1(0.4)$ & $2(1.3)$ & $0(0)$ \\
$1(0.2)$ & $1(0.4)$ & $0(0)$ & $0(0)$ \\
\hline
\end{tabular}

felt that personal meaningfulness of the research and benefit to friends and family were important in their decision to participate, while $75 \%$ stated that it was important to participate if research provided information to improve their personal health. Two-thirds of the population related that it was important that the research improve their health or provide information they did not previously know. Only $20 \%$ of participant's felt that the value of incentives was an important factor in the decision to participate in research. These results did not materially differ between cases, controls, or relatives.

Participants with cancer at baseline or at the time of the survey completion 
endorsed the personal meaningfulness of research as a factor for participation in research compared to participants without cancer $(\mathrm{OR}=0.61,0.42-0.89 ; \mathrm{OR}=$ $0.62,0.42$ - 0.91) (Table 3). Those with a more advanced stage of cancer were significantly more likely to participate in research because they felt that the research could benefit their family $(\mathrm{OR}=2.72,0.99-7.50)$. While all cases were significantly more likely to feel that the research must be meaningful to them personally compared to controls $(\mathrm{OR}=1.56,1.05-2.34)$, women were $50 \%$ more likely than men to believe that a family benefit is an important determinant of research participation $(\mathrm{OR}=1.73,1.16-2.58)$.

As shown in Table 4, almost all of participants felt that the researcher trustworthiness, institutional trustworthiness, and security of stored data and samples are very important or somewhat important when determining whether to provide a biological sample. Receiving a personal report about individual genetic risks and/or benefits, as well as the security of the data and samples were cited by $86 \%$ and $87 \%$ of participants as important factors in providing a biological sample. Women were twice as likely as men to endorse researcher trustworthiness as an important factor in deciding whether to provide a biological sample $(\mathrm{OR}=$ 2.0, 1.03 - 3.90) (Table 5). Cases were significantly more likely than controls to feel that receiving individual genetic risks was important $(\mathrm{OR}=1.92,1.27$ 2.90 ), and a history of cancer at baseline or when the survey was administered increased the importance of receiving genetic risks and/or benefits as a factor for participation in biological sampling $(\mathrm{OR}=0.54,0.37-0.80$; $\mathrm{OR}=0.61,0.41$ 0.90).

Table 3. Adjusted ordinal regression by participant characteristics.

\begin{tabular}{lcccc}
\hline & & OR & $95 \%$ CI & p-value \\
\hline $\begin{array}{l}\text { The reputation of the research institution } \\
\text { or researcher }\end{array}$ & Subject Type & & & \\
& Control vs Case & 0.92 & $0.55,1.54$ & 0.76 \\
& Relative vs Case & 0.87 & $0.43,1.75$ & 0.69 \\
& Gender & 1.51 & $0.92,2.47$ & 0.10 \\
& Cancer at baseline & 1.12 & $0.70,1.81$ & 0.64 \\
& Cancer at survey & 1.09 & $0.67,1.78$ & 0.72 \\
& Stage of cancer & 1.52 & $0.47,4.90$ & 0.48 \\
The value of incentives (for example, gift & Subject Type & & & \\
cards or cash) & Control vs Case & 0.98 & $0.66,1.45$ & 0.91 \\
& Relative vs Case & 1.47 & $0.84,2.57$ & 0.18 \\
& Gender & 0.83 & $0.56,1.22$ & 0.33 \\
& Cancer at baseline & 0.78 & $0.54,1.12$ & 0.18 \\
& Cancer at survey & 0.71 & $0.49,1.04$ & 0.08 \\
& Stage of cancer & 1.06 & $0.40,2.82$ & 0.90 \\
\hline
\end{tabular}




\section{Continued}

The research must be meaningful to me personally

The research will improve my health

The research will provide information I can use to improve my health

The research will provide information about me I didn't know

The research could benefit my family

The research could benefit people I know

\section{Subject Type}

$\begin{array}{cccc}\text { Control vs Case } & 1.56 & 1.05,2.34 & 0.03 \\ \text { Relative vs Case } & 1.15 & 0.67,2.00 & 0.61 \\ \text { Gender } & 1.15 & 0.78,1.70 & 0.49 \\ \text { Cancer at baseline } & 0.61 & 0.42,0.89 & 0.01 \\ \text { Cancer at survey } & 0.62 & 0.42,0.91 & 0.02 \\ \text { Stage of cancer } & 1.56 & 0.59,4.14 & 0.37 \\ \text { Subject Type } & & & \\ \text { Control vs Case } & 1.25 & 0.85,1.83 & 0.27 \\ \text { Relative vs Case } & 0.81 & 0.46,1.42 & 0.47 \\ \text { Gender } & 1.03 & 0.70,1.50 & 0.89 \\ \text { Cancer at baseline } & 0.77 & 0.54,1.11 & 0.17 \\ \text { Cancer at survey } & 0.79 & 0.54,1.13 & 0.20 \\ \text { Stage of cancer } & 1.54 & 0.59,4.01 & 0.379\end{array}$

Subject Type

$\begin{array}{cccc}\text { Control vs Case } & 1.27 & 0.86,1.88 & 0.223 \\ \text { Relative vs Case } & 0.95 & 0.54,1.68 & 0.858 \\ \text { Gender } & 1.18 & 0.80,1.74 & 0.39 \\ \text { Cancer at baseline } & 0.77 & 0.54,1.11 & 0.16 \\ \text { Cancer at survey } & 0.74 & 0.51,1.08 & 0.12 \\ \text { Stage of cancer } & 1.53 & 0.58,4.05 & 0.40\end{array}$

Subject Type

$\begin{array}{cccc}\text { Control vs Case } & 1.05 & 0.71,1.54 & 0.82 \\ \text { Relative vs Case } & 1.04 & 0.60,1.77 & 0.90 \\ \text { Gender } & 1.01 & 0.69,1.47 & 0.97 \\ \text { Cancer at baseline } & 0.85 & 0.60,1.22 & 0.38 \\ \text { Cancer at survey } & 0.88 & 0.61,1.26 & 0.48 \\ \text { Stage of cancer } & 2.4 & 0.91,6.34 & 0.08\end{array}$

Subject Type

$\begin{array}{cccc}\text { Control vs Case } & 1.32 & 0.87,2.02 & 0.19 \\ \text { Relative vs Case } & 0.85 & 0.46,1.54 & 0.58 \\ \text { Gender } & 1.51 & 1.00,2.27 & 0.05 \\ \text { Cancer at baseline } & 0.81 & 0.54,1.19 & 0.28 \\ \text { Cancer at survey } & 0.87 & 0.58,1.31 & 0.51 \\ \text { Stage of cancer } & 2.72 & 0.99,7.50 & 0.05\end{array}$

Subject Type

$\begin{array}{llll}\text { Control vs Case } & 1.44 & 0.95,2.18 & 0.08\end{array}$

$\begin{array}{llll}\text { Relative vs Case } \quad 0.9 \quad 0.51,1.61 & 0.73\end{array}$ 


\section{Continued}

\begin{tabular}{lcccc}
\hline Gender & 1.73 & $1.16,2.58$ & 0.01 \\
& Cancer at baseline & 0.74 & $0.51,1.09$ & 0.13 \\
Cancer at survey & 0.78 & $0.53,1.15$ & 0.21 \\
Stage of cancer & 2.56 & $0.95,6.89$ & 0.06 \\
The research could benefit society & Subject Type & & & \\
& Control vs Case & 1.42 & $0.17,1.22$ & 0.73 \\
& Relative vs Case & & N/A* & \\
Gender & 1.49 & $0.17,1.32$ & 0.70 \\
& Cancer at baseline & 2.24 & $0.27,4.62$ & 0.49 \\
Cancer at survey & 1.53 & $0.18,3.23$ & 0.72 \\
& Stage of cancer & & N/A & \\
\hline
\end{tabular}

Table 4. Frequency (\%) of responses by participant type to the question: Imagine you were asked to provide health information about yourself and a biological sample (such as blood or saliva) for genetic analysis as part of your participation in a research study. Please indicate the importance of each of the following in determining whether or not you would participate.

\begin{tabular}{|c|c|c|c|c|}
\hline & Total & Cases & Controls & Relatives \\
\hline \multicolumn{5}{|c|}{ The researcher is trustworthy } \\
\hline Very important & $405(90.3)$ & $207(91.6)$ & $137(88.4)$ & $61(91.0)$ \\
\hline Somewhat important & $39(8.7)$ & $17(7.5)$ & $17(11.0)$ & $5(7.5)$ \\
\hline Not very important & $2(0.5)$ & $0(0)$ & $1(0.6)$ & $1(1.5)$ \\
\hline Not at all important & $2(0.5)$ & $2(0.9)$ & $0(0)$ & $0(0)$ \\
\hline \multicolumn{5}{|c|}{$\begin{array}{l}\text { The institution where the research is being } \\
\text { conducted is trustworthy }\end{array}$} \\
\hline Very important & $409(91.3)$ & $205(90.7)$ & $142(91.6)$ & $62(92.5)$ \\
\hline Somewhat important & $36(8.0)$ & $19(8.4)$ & $12(7.7)$ & $5(7.5)$ \\
\hline Not very important & $1(0.2)$ & $0(0)$ & $1(0.6)$ & $0(0)$ \\
\hline Not at all important & $2(0.5)$ & $2(0.9)$ & $0(0)$ & $0(0)$ \\
\hline \multicolumn{5}{|c|}{$\begin{array}{l}\text { I will receive a personal report about my } \\
\text { individual genetic risks and/or benefits }\end{array}$} \\
\hline Very important & $239(53.9)$ & $133(59.1)$ & $69(45.4)$ & $37(56.1)$ \\
\hline Somewhat important & $142(32.1)$ & $73(32.4)$ & $53(34.9)$ & $16(24.2)$ \\
\hline Not very important & $48(10.8)$ & $15(6.7)$ & $25(16.4)$ & $8(12.1)$ \\
\hline Not at all important & $14(3.2)$ & $4(1.8)$ & $5(3.3)$ & $5(7.6)$ \\
\hline \multicolumn{5}{|c|}{ Data and samples are stored securely } \\
\hline Very important & $366(82.3)$ & $186(82.7)$ & $123(79.9)$ & $57(86.4)$ \\
\hline Somewhat important & $66(14.8)$ & $33(14.7)$ & $27(17.5)$ & $6(9.1)$ \\
\hline Not very important & $12(2.7)$ & $6(2.7)$ & $4(2.6)$ & $2(3.0)$ \\
\hline Not at all important & $1(0.2)$ & $0(0)$ & $0(0)$ & $1(1.5)$ \\
\hline
\end{tabular}


Table 5. Adjusted ordinal regression by participant characteristics.

\begin{tabular}{|c|c|c|c|c|}
\hline & Model & OR & $95 \% \mathrm{CI}$ & $\mathrm{p}$-value \\
\hline & Subject Type & & & \\
\hline \multirow[t]{6}{*}{ The researcher is trustworthy } & Control vs Case & 1.46 & $0.72,2.96$ & 0.30 \\
\hline & Relative vs Case & 0.97 & $0.35,2.63$ & 0.95 \\
\hline & Gender & 2.00 & $1.03,3.90$ & 0.04 \\
\hline & Cancer at baseline & 1.01 & $0.52,1.95$ & 0.99 \\
\hline & Cancer at survey & 0.93 & $0.48,1.83$ & 0.84 \\
\hline & Stage of cancer & 0.35 & $0.04,3.08$ & 0.34 \\
\hline \multirow{7}{*}{$\begin{array}{l}\text { The institution where the research is being } \\
\text { conducted is trustworthy }\end{array}$} & Subject Type & & & \\
\hline & Control vs Case & 0.94 & $0.44,1.99$ & 0.86 \\
\hline & Relative vs Case & 0.75 & $0.26,2.17$ & 0.60 \\
\hline & Gender & 1.61 & $0.79,3.27$ & 0.19 \\
\hline & Cancer at baseline & 1.39 & $0.69,2.82$ & 0.40 \\
\hline & Cancer at survey & 1.37 & $0.66,2.84$ & 0.40 \\
\hline & Stage of cancer & 0.31 & $0.04,2.71$ & 0.30 \\
\hline \multirow{7}{*}{$\begin{array}{l}\text { I will receive a personal report about my } \\
\text { individual genetic risks and/or benefits }\end{array}$} & Subject Type & & & \\
\hline & Control vs Case & 1.92 & $1.27,2.90$ & 0.002 \\
\hline & Relative vs Case & 1.25 & $0.69,2.25$ & 0.46 \\
\hline & Gender & 1.15 & $0.77,1.72$ & 0.49 \\
\hline & Cancer at baseline & 0.54 & $0.37,0.80$ & 0.002 \\
\hline & Cancer at survey & 0.61 & $0.41,0.90$ & 0.01 \\
\hline & Stage of cancer & 0.58 & $0.19,1.74$ & 0.33 \\
\hline \multirow{7}{*}{ Data and samples are stored securely } & Subject Type & & & \\
\hline & Control vs Case & 1.24 & $0.72,2.16$ & 0.44 \\
\hline & Relative vs Case & 0.78 & $0.33,1.82$ & 0.56 \\
\hline & Gender & 1.60 & $0.94,2.73$ & 0.08 \\
\hline & Cancer at baseline & 0.94 & $0.55,1.58$ & 0.80 \\
\hline & Cancer at survey & 0.95 & $0.55,1.62$ & 0.85 \\
\hline & Stage of cancer & & $\mathrm{N} / \mathrm{A}^{*}$ & \\
\hline
\end{tabular}

\section{Discussions}

The purpose of this study was to identify factors that motivate people to participate in a research study that has components required for participation similar to the PMI. We found that the two most important motivational factors for the decision to participate in an observational research study included a benefit to society and the reputation of the research institution. This is consistent with previous studies that have shown individual benefits, social value, and trust of 
the physicians and/or research institution are motivators for study participants [12] [13] [14] [15] [16]. To our knowledge, only one previous study also used quantitative methods to evaluate these motivators to participation in an observational setting and, similar to our results, found that $87 \%$ of respondents cited future health benefits to society and oneself as important reasons to participate in health research [16].

It has been suggested that the altruistic component of motivation to participate in research may be related to a ratio of risks to benefits [13]. Compared to a cohort study, the benefits of participation in a clinical trial might be more concrete and observable to research participants. While this risk-benefit ratio is diminished in a cohort study, we found that a benefit to society is still the most important factor in determining participation.

Participants with a history of cancer were more likely to participate if the research was personally meaningful. In addition, stage of cancer was also associated with motivation to participate, and those with a higher stage were more likely to view the benefit to family members as an important motivator. It is possible that those with late stage cancer are more eager to obtain timely benefits from research studies. This study also found that women were significantly more likely than men to endorse a family benefit as an important motivator for research participation. To our knowledge, we are the first to identify this gender difference in motivation to participate in research. Surprisingly, only $20 \%$ of participants felt that incentives were an important factor in their decision to participate in research. The "leverage-saliency theory" describes the probability of participating in a survey as a combination of survey-specific factors (for example, study topic and who is doing the study), participant specific factors (for example, concerns about privacy), and the participant's social and physical environment [21]. The impact of an incentive is weighed against the absence or presence of other factors impacting the motivation to participate [22]. It has been shown that monetary incentives have a greater impact when the study topic has little salience [21] [23] [24]. It is possible that in this study population, comprised largely of an older, white group of cancer cases and their relatives, strong participant and study factors outweighed the need for incentives [25] [26] [27] [28]. In addition, because education is a proxy for SES, people may value time more than money. In our highly educated study population, participants may weigh the time devoted to the research study with the benefits it provides to themselves, their families, and society.

Researcher and institution trustworthiness as well as data security were most important to participants when deciding whether to provide a biological sample. The finding of trustworthiness is consistent with others [29]. Gender differences related to trust have previously been shown; women show less distrust of medical researchers compared to men when asked to participate in a clinical trial [20]. This is consistent with our finding that women were significantly more likely to feel that trustworthiness is an important motivating factor in providing a biospecimen. Only one previous study evaluated gender differences related to 
trust and the donation of a biological specimen and did not find a significant difference [29]. However, the study was conducted among twin pairs and therefore matched on both genetics and environment, potentially eliminating any differences in trust. In addition, it is possible that a difference in demographics accounts for the lack of association. Our population was older (mean age of 63.6 years compared to 37.5 years) and highly educated (85\% with a greater than a high school education compared to only $50 \%$ having completed high school), with both age and education significantly associated with trust. Consistent with others [30], this study also demonstrated that among participants with a history of cancer, receiving genetic results is a strong motivator for donation of a biologic sample.

These results have implications for interventions designed to improve participation rates in cohort studies. One strategy for increasing or maintaining participation is always to make the altruistic motivations a salient part of promotional and instructional materials. If contributing to science or giving back to people with similar issues is an important motivation, then cohort studies should constantly find ways of showing participants how their contributions matter. This could take the form of printed words, like a newsletter or other correspondence, or could take the form of an image or logo that conveys assistance or scientific discovery. In every interaction with participants there is an opportunity to remind them of how their time and effort as participants will make a contribution that is both unique and valuable. These kinds of strategies can actually be tested and evaluated in the context of large-scale research projects [31] and, combined with other activities could form a battery of participation strategies for cohort studies as well as clinical trials.

Because this study population was limited to a highly educated and mostly white group of older adults, it is possible these results may not be generalizable to all populations. In addition, our study population was already willingly enrolled in a research study and it is possible that these motivators may differ from a general population. Although 35 participants in the control group reported cancer at baseline and 35 participants without cancer at baseline reported cancer at the time of the survey, we still found significant differences between cases and controls in several motivational factors. While some differences in motivational factors by stage of cancer were seen, these findings were based on small numbers and further conclusions are not possible. Finally, we were unable to evaluate motivational differences related to participation in research by cancer site because of small numbers for most cancer types. Given the gender differences seen in this study however, further research is needed to evaluate if a history of female-specific cancers impact research participation motivation.

Participant enrollment into the national population-based PMI cohort is quickly approaching. The major advantage of a population-based observational cohort design is external validity, it is therefore important to understand factors that motivate subjects to participate in this type of research study. Maximizing recruitment and limiting attrition will increase the representativeness of the 
population and generalizability of study results.

\section{Acknowledgements}

The authors wish to thank the individuals enrolled in the NWCGR for their ongoing participation in and contribution to cancer research. They also acknowledge and thank Lesley Pfeiffer, Anne Renz, Joan Scott and David Kaufmann for their work contributing to the earlier stages of this project. This research was supported by NIH grant\# R01CA149051 to Karen Edwards (PI), "Identification of Issues and Expectations of Subjects Participating in Genetic Studies of Cancer".

\section{Conflicts of Interest}

The authors declare no conflicts of interest regarding the publication of this paper.

\section{References}

[1] Collins, F.S. and Varmus, H. (2015) A New Initiative on Precision Medicine. The New England Journal of Medicine, 372, 793-795. https://doi.org/10.1056/NEJMp1500523

[2] Kasner, S.E., Del Giudice, A., Rosenberg, S., et al. (2009) Who Will Participate in Acute Stroke Trials? Neurology, 72, 1682-1688. https://doi.org/10.1212/WNL.0b013e3181a55fbe

[3] Eagan, T.M.L., Eide, G.E., Gulsvik, A. and Bakke P.S. (2002) Nonresponse in a Community Cohort Study: Predictors and Consequences for Exposure-Disease Associations. Journal of Clinical Epidemiology, 55, 775-781. https://doi.org/10.1016/S0895-4356(02)00431-6

[4] Plummer, P., Jackson, S., Konarski, J., et al. (2002) Making Epidemiologic Studies Responsive to the Needs of Participants and Communities: The Carolina Breast Cancer Study Experience. Environmental and Molecular Mutagenesis, 39, 96-101. https://doi.org/10.1002/em.10045

[5] Vinther-Larsen, M., Riegels, M., Rod, M.H., Schiotz, M., Curtis, T. and Gronbaek, M. (2010) The Danish Youth Cohort: Characteristics of Participants and Non-Participants and Determinants of Attrition. Scandinavian Journal of Public Health, 38, 648-656. https://doi.org/10.1177/1403494810374222

[6] De Angelis, C., Drazen, J.M., Frizelle, F.A., et al. (2005) Clinical Trial Registration: A Statement from the International Committee of Medical Journal Editors. Arteriosclerosis, Thrombosis, and Vascular Biology, 25, 873-874.

[7] Constantinou, M., Jhanji, V., Chiang, P.P., et al. (2012) Determinants of Informed Consent in a Cataract Surgery Clinical Trial: Why Patients Participate. Canadian Journal of Ophthalmology, 47, 118-123. https://doi.org/10.1016/j.jcjo.2012.01.006

[8] Shah, A., Efstathiou, J.A., Paly, J.J., et al. (2012) Prospective Preference Assessment of Patients' Willingness to Participate in a Randomized Controlled Trial of Intensity-Modulated Radiotherapy versus Proton Therapy for Located Prostate Cancer. International Journal of Radiation Oncology, Biology, Physics, 83, e13-e19. https://doi.org/10.1016/j.ijrobp.2011.11.072

[9] Markusse, I.M., Dirven, I., Han, K.H., et al. (2015) Continued Participation in a 
Ten-Year Tight Control Treat-to-Target Study in Rheumatoid Arthritis: Why Keep Patients Doing Their Best? Arthritis Care \& Research (Hoboken), 67, 739-745. https://doi.org/10.1002/acr.22540

[10] McCann, S.K., Campbell, M.K. and Etwistle, V.A. (2010) Reasons for Participating in Randomized Controlled Trials: Conditional Altruism and Considerations for Self. Trials, 11, 31. https://doi.org/10.1186/1745-6215-11-31

[11] Dellborg, H., Hultsberg-Olsson, G. and Dellborg, M. (2016) Why Do Patients Participate in Long-Term Cardiovascular Trials?-A Questionnaire-Based Study. Scandinavian Cardiovascular Journal, 19, 83-87. https://doi.org/10.3109/14017431.2015.1133843

[12] Kirkland, S.A., Raina, P.S., Wolfson, C., Strople, G., et al. (2009) Exploring the Acceptability and Feasibility of Conducting a Large Longitudinal Population-Based Study in Canada. Canadian Journal on Aging, 283, 231-242. https://doi.org/10.1017/S0714980809990043

[13] Hallowell, N., Cooke, S., Crawford, G., Lucassen, A., Parker, M. and Snowdon, C. (2010) An Investigation of Patients' Motivations for Their Participation in Genetics-Related Research. Journal of Medical Ethics, 36, 37-45. https://doi.org/10.1136/jme.2009.029264

[14] Slegers, C., Zion, D., Glass, D., Kelsall, H., et al. (2015) Why Do People Participate in Epidemiological Research? Journal of Bioethical Inquiry, 12, 227-237. https://doi.org/10.1007/s11673-015-9611-2

[15] Matsui, K. and Kita, Y. (2010) Why Do People Consent to Participate in Genetic Epidemiological Studies? Nihon Koshu Eisei Zasshi, 57, 977-987.

[16] Teschke, K., Marino, R., Chu, J.K., Taui, M.A., et al. (2010) Public Opinions about Participating in Health Research. Canadian Journal of Public Health, 101, 159-164.

[17] Galea, S. and Tracey, M. (2007) Participation Rates in Epidemiologic Studies. Annals of Epidemiology, 17, 643-653. https://doi.org/10.1016/j.annepidem.2007.03.013

[18] Condit, C.M., Korngiebel, D.M., Pfeifer, M., Renz, A.D., Bowen, D.J., Kaufman, D., Mercer Kollar, L.M. and Edwards, K. (2015) What Should Be the Character of the Researcher-Participant Relationship? Views of Participants in a Longstanding Cancer Genetic Registry. IRB: Ethics \& Human Research, 37, 1-10.

[19] Goodman, D., Johnson, C.O., Wenzel, L., Bowen, D.J., Condit, C.M. and Edwards, K.L. (2016) Consent Issues in Genetic Research: Views of Research Participants. Public Health Genomics, 19, 220-228. https://doi.org/10.1159/000447346

[20] MASS Package (Code for Ordinal Logistic Regression: Venables, W.N. and Ripley, B.D. (2002) Modern Applied Statistics with S. 4th Edition, Springer, New York.

[21] Groves, R.M., Singer, E. and Corning, A.D. (2000) Leverage-Saliency Theory of Survey Participation: Description and Illustration. Public Opinion Quarterly, 64, 299-308. https://doi.org/10.1086/317990

[22] Singer, E. and Couper, M.P. (2008) Do Incentives Exert Undue Influence on Survey Participation? Experimental Evidence. Journal of Empirical Research on Human Research Ethics, 3, 49-56. https://doi.org/10.1525/jer.2008.3.3.49

[23] Martinez-Ebers, V. (1997) Using Monetary Incentives with Hard-to-Reach Populations in Panel. International Journal of Public Opinion Research, 9, 77-86. https://doi.org/10.1093/ijpor/9.1.77

[24] Berlin, M., Mohadjer, L., Waksberg, J., Kolstad, A., et al. (1992) An Experiment in Monetary Incentives. Proceedings of Survey Research Methods Section, American Statistical Association, Alexandria, VA, 1992, 393-398. 
[25] Brown, J.G., Joyce, K.E., Stacey, D. and Thomson, R.G. (2015) Patients or Volunteers? The Impact of Motivation for Trial Participation on the Efficacy of Patient Decision Aids: A Secondary Analysis of a Cochrane Systematic Review. Medical Decision Making, 35, 419-435. https://doi.org/10.1177/0272989X15579172

[26] Dhalla, S. and Poole, G. (2013) Motivators to Participation in Medical Trials: The Application of Social and Personal Categorization. Psychology, Health \& Medicine, 18, 664-675. https://doi.org/10.1080/13548506.2013.764604

[27] Elwyn, G., Scholl, I., Tietbohl, C., Mann, M., Edwards, A.G., Clay, C., Légaré, F., van der Weijden, T., Lewis, C.L., Wexler, R.M. and Frosch, D.L. (2013) "Many Miles to Go...": A Systematic Review of the Implementation of Patient Decision Support Interventions into Routine Clinical Practice. BMC Medical Informatics and Decision Making, 13, S14. https://doi.org/10.1186/1472-6947-13-S2-S14

[28] Stunkel, L. and Grady, C. (2011) More than the Money: A Review of the Literature Examining Healthy Volunteer Motivations. Contemporary Clinical Trials, 32, 342-352. https://doi.org/10.1016/j.cct.2010.12.003

[29] Toccaceli, V., Fagnani, C., Gigantesco, A., Brescianini, S., D’Ippolito, C. and Stazi, M.A. (2014) Attitudes and Willingness to Donate Biological Samples for Research among Potential Donors in the Italian Twin Register. Journal of Empirical Research on Human Research Ethics, 9, 39-47. https://doi.org/10.1177/1556264614540601

[30] Ding, E.L., Powe, N.R., Manson, J.E., Sherber, J.S. and Braunstein, J. (2007) Sex Differences in Perceived Risks, Distrust, and Willingness to Participate in Clinical trials: A Randomized Study of Cardiovascular Prevention Trials. JAMA Internal Medicine Journal, 167, 905-912. https://doi.org/10.1001/archinte.167.9.905

[31] Bowen, D.J., Thornquist, M., Goodman, G., Omenn, G.S., Anderson, K., Barnett, M. and Valanis, B. (2000) Effects of Incentives on Participation in a Randomized Chemoprevention Trial. Journal of Health Psychology, 5, 109-115.

https://doi.org/10.1177/135910530000500103 


\section{Appendix 1}

When making the decision to participate in a research study, how important are the following to you?

1) The reputation of the research institution or researcher.

a) Very important

b) Somewhat important

c) Not very important

d) Not at all important

2) The value of incentives (for example, gift cards or cash)

a) Very important

b) Somewhat important

c) Not very important

d) Not at all important

3) The research must be meaningful to me personally.

a) Very important

b) Somewhat important

c) Not very important

d) Not at all important

4) The research will improve my health.

a) Very important

b) Somewhat important

c) Not very important

d) Not at all important

5) The research will provide information I can use to improve my health.

a) Very important

b) Somewhat important

c) Not very important

d) Not at all important

6) The research will provide information about me I didn't know.

a) Very important

b) Somewhat important

c) Not very important

d) Not at all important

7) The research could benefit my family.

a) Very important

b) Somewhat important

c) Not very important

d) Not at all important

8) The research could benefit people I know.

a) Very important

b) Somewhat important

c) Not very important

d) Not at all important 
9) The research could benefit society.
a) Very important
b) Somewhat important
c) Not very important
d) Not at all important

Imagine you were asked to provide health information about yourself and a biological sample (such as blood or saliva) for genetic analysis as part of your participation in a research study.

Please indicate the importance of each of the following in determining whether or not you would participate.

10) The researcher is trustworthy.

a) Very important

b) Somewhat important

c) Not very important

d) Not at all important

11) The institution where the research is being conducted is trustworthy.

a) Very important

b) Somewhat important

c) Not very important

d) Not at all important

12) I will receive a personal report about my individual genetic risks and/or benefits.
a) Very important
b) Somewhat important
c) Not very important
d) Not at all important
13) Data and samples are stored securely.
a) Very important
b) Somewhat important
c) Not very important
d) Not at all important 